\title{
Avaliação da eficiência de diferentes coagulantes utilizados em uma Estação de Tratamento de Águas
}

\author{
Evaluation of efficiency of different coagulants used in water treatment plant
}

Evaluación de la eficiencia de diferentes coagulantes utilizados en la planta de tratamiento de agua

Cristiane Daliassi Ramos de Souza ORCID: https://orcid.org/0000-0003-3857-9719 Universidade Federal do Amazonas, Brasil E-mail: cdaliassi@ufam.edu.br

Iago Bruno Pacheco Ferreira

ORCID: https://orcid.org/0000-0002-0014-7323

Universidade Federal do Amazonas, Brasil

E-mail: iagopacheco.ib@gmail.com

\begin{abstract}
Resumo
Na região Amazônica situa-se uma das maiores reservas de água doce do mundo, onde muitas vezes existe o paradoxo de que em muitas cidades ribeirinhas, a população não é comtemplada com água tratada e de qualidade. O Rio Solimões é um dos maiores rios atualmente, onde muitas pessoas residem ao longo de sua passagem. O objetivo deste trabalho foi avaliar a ação coagulante de três produtos comerciais (Sulfato de Alumínio, Cloreto Férrico e Policloreto de Alumínio) para utilização na Estação de Tratamento de Águas do Careiro da Várzea. A metodologia foi dividida em três etapas, iniciou-se com o monitoramento das análises físico-químicas e bacteriológicas do manancial no local de captação das águas. Em seguida foram realizados ensaios de bancada utilizando Jar Test com concentrações de 7 a 25 ppm, para cada coagulante, para verificar as características ótimas do processo. Por fim, executaram-se os testes na ETA da cidade durante 24 horas e foram monitorados os parâmetros de turbidez e cor. Os resultados mostraram que o manancial apresentou características básicas, com alta turbidez e cor. Nos ensaios laboratoriais, assim como no aumento de escala constatou-se que o coagulante comercial, cloreto férrico, apresentou uma melhor eficiência a 20 ppm com condições operacionais na ETA de 0,2 ppm de floculante e pH 7.
\end{abstract}

Palavras-chave: Rio Solimões; Estação de tratamento de águas; Coagulantes; Jar Test.

\begin{abstract}
In Amazon region is located one of the largest reserves of fresh water in the world, where there is often the paradox that in many riverside cities, the population is not provided with treated and quality water. The Solimões River is one of the largest rivers today, where many people reside along its passage. The objective of this work was to evaluate the coagulant action of three commercial products (Aluminum Sulfate, Ferric Chloride and Polyaluminium Chloride) for use in the Water Treatment Plant of Careiro da Várzea. The methodology was divided into three stages, starting with the monitoring of physico-chemical and bacteriological analyzes of the water source at the water catchment site. Then, bench tests were carried out using Jar Test with concentrations from 7 to $25 \mathrm{ppm}$, for each coagulant, to verify the optimal characteristics of the process. Finally, the tests were carried out at the city's WTP for 24 hours and the parameters of turbidity and color were monitored. The results showed that the source presented basic characteristics, with high turbidity and color. In laboratory tests, as well as in the scale-up, it was found that the commercial coagulant, ferric chloride, presented better efficiency at $20 \mathrm{ppm}$ with WTP operating conditions of $0.2 \mathrm{ppm}$ flocculant and $\mathrm{pH} 7$.
\end{abstract}

Keywords: Solimões River; Water treatment plant; Coagulants; Jar Test.

\section{Resumen}

En la región amazónica se encuentra una de las mayores reservas de agua dulce del mundo, donde suele darse la paradoja de que en muchas ciudades ribereñas la población no cuenta con agua tratada y de calidad. El río Solimões es uno de los ríos más grandes de la actualidad, donde residen muchas personas a lo largo de su paso. El objetivo de este trabajo fue evaluar la acción coagulante de tres productos comerciales (Sulfato de Aluminio, Cloruro Férrico y Cloruro de Polialuminio) para su uso en la Planta de Tratamiento de Agua de Careiro da Várzea. La metodología se dividió en tres etapas, comenzando con el seguimiento de los análisis fisicoquímicos y bacteriológicos de la fuente de agua en el sitio de captación de agua. Luego, se realizaron pruebas de banco utilizando Jar Test con concentraciones de 7 a 25 ppm, para cada coagulante, para verificar las características óptimas del proceso. Finalmente, las pruebas se realizaron en la ETA de la ciudad durante 24 horas y se monitorearon los parámetros de turbidez y color. Los resultados mostraron que la fuente presenta características básicas, con alta turbidez y color. En las pruebas de 
laboratorio, así como en el escalado, se encontró que el coagulante comercial, el cloruro férrico, mostró una mejor eficiencia a 20 ppm con condiciones de operación ETA de 0,2 ppm de floculante y pH 7.

Palabras clave: Río Solimões; Planta de tratamiento de agua; Coagulantes; Jar Test.

\section{Introdução}

A água é um elemento muito importante para os seres vivos, além de ser importante para a manutenção do clima na Terra (Sun et al., 2016), e a Amazônia é conhecida por sua elevada disponibilidade hídrica, que se distribui por uma vasta área geográfica com lagos, rios com grandes variabilidades tanto na extensão e largura, quanto no volume de água. O rio Solimões é o principal canal coletor de águas da maior e mais volumosa bacia hidrográfica do mundo. Transporta grandes quantidades de sólidos suspensos, responsáveis por sua aparência lamacenta e amarelada. Suas águas são extremamente turvas, apresentam pouco material orgânico e são levemente alcalinas. Apesar disto, muitas comunidades ribeirinhas sofrem com a falta de saneamento básico, e isso acaba sendo um risco para a saúde das pessoas que residem nessas áreas (Queiroz \& Tomaz Neto, 2019).

A cidade do Careiro da Várzea é a menor do Estado do Amazonas em área territorial que corresponde a $2.631,13 \mathrm{~km}^{2}$, representando 0,1675\% do Estado, 0,0683\% da Região e 0,031\% de todo o território brasileiro. A Figura 1 apresenta a

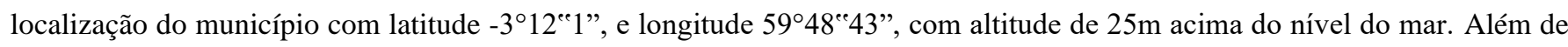
Manaus, situada ao norte do Careiro da Várzea, este se limita ao sul com as cidades de Manaquiri e Autazes, ao leste com Itacoatiara, a oeste com Iranduba (Mendes, 2018).

Figura 1. Localização do município do Careiro da Várzea/AM.

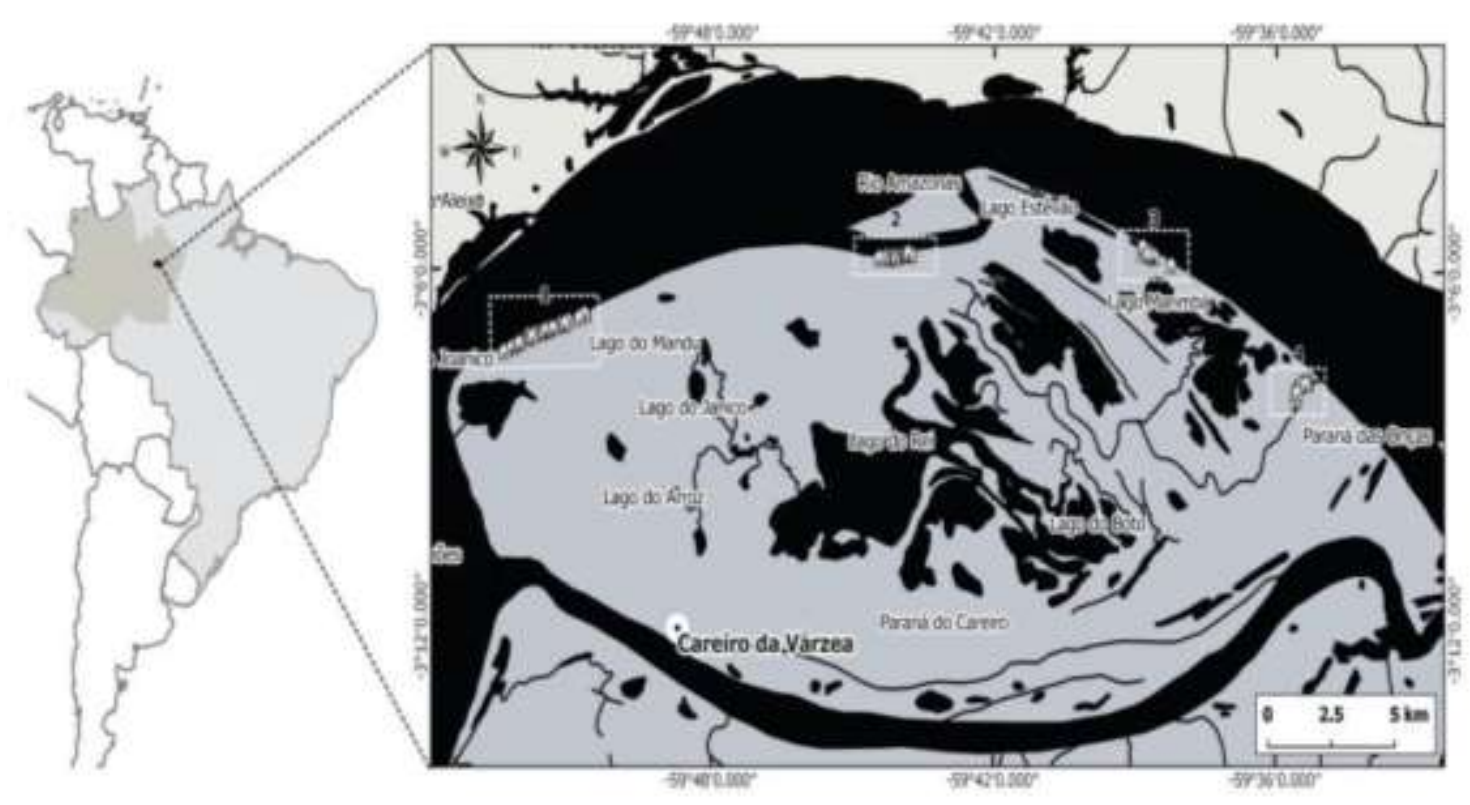

Fonte: Adaptado de Mendes (2018).

O tratamento de água é um processo importante, pois influencia na qualidade da água utilizada pela população (Von Sperling, 2014). Considera-se que o modelo mais utilizado no Brasil, dentre diversos, é o tratamento em ciclo completo, que engloba as etapas de coagulação, floculação, decantação, filtração e desinfecção. (Libânio, 2010). Devido a coagulação ser uma das primeiras etapas do processo de uma Estação de Tratamento de Água (ETA), torna-se imprescindível estudos mais aprofundados sobre os tipos de coagulantes utilizados no processo (Santos et al., 2018). Esta etapa consiste em adicionar o coagulante ao afluente de água bruta na ETA e, assim promover por meio de mistura rápida, hidráulica ou mecânica, a 
homogeneização. (Pavanelli, 2001). Como as reações que ocorrem no tratamento físico-químico são bastante complexas é essencial estabelecer um pH ótimo de floculação, bem como determinar a concentração (dosagem) do coagulante necessária para a separação dos poluentes em suspensão. (Cavalcanti, 2016).

Diante do exposto, o objetivo deste trabalho foi avaliar a performance de três coagulantes comerciais, através de estudos de bancada e piloto, para determinar a dosagem ótima a ser utilizada em uma ETA no município do Careiro da Várzea.

\section{Metodologia}

A metodologia foi dividida em três partes. A primeira é referente ao monitoramento das águas do Rio Solimões no ponto de captação da Estação de Tratamento de Águas (ETA), localizada na cidade do Careiro da Várzea, Amazonas. A segunda parte corresponde aos ensaios de bancada realizados por meio do equipamento Jar Test em laboratório. Por fim, a terceira parte está relacionada ao aumento de escala, onde foram realizados os testes com os produtos químicos comerciais na própria ETA. Em todas as etapas foram verificadas conformidade com a Portaria de Consolidação MS/GM n ${ }^{\circ} 05$, de 28 de setembro de 2017, Anexo XX (Brasil, 2017).

\subsection{Monitoramento das águas do Rio Solimões no ponto de captação}

É de fundamental importância o conhecimento das características físico-químicas do manancial no qual realiza-se o tratamento da água, portanto elaborou-se um plano para o monitoramento das águas do Rio Solimões. A água do manancial investigada foi coletada no ponto de captação situado no flutuante localizado na cidade do Careiro da Várzea, durante os meses de setembro e outubro de 2020, período que compreende a seca amazônica (Figura 2).

Figura 2. Localização do flutuante (marcador amarelo) no município do Careiro da Várzea-AM.

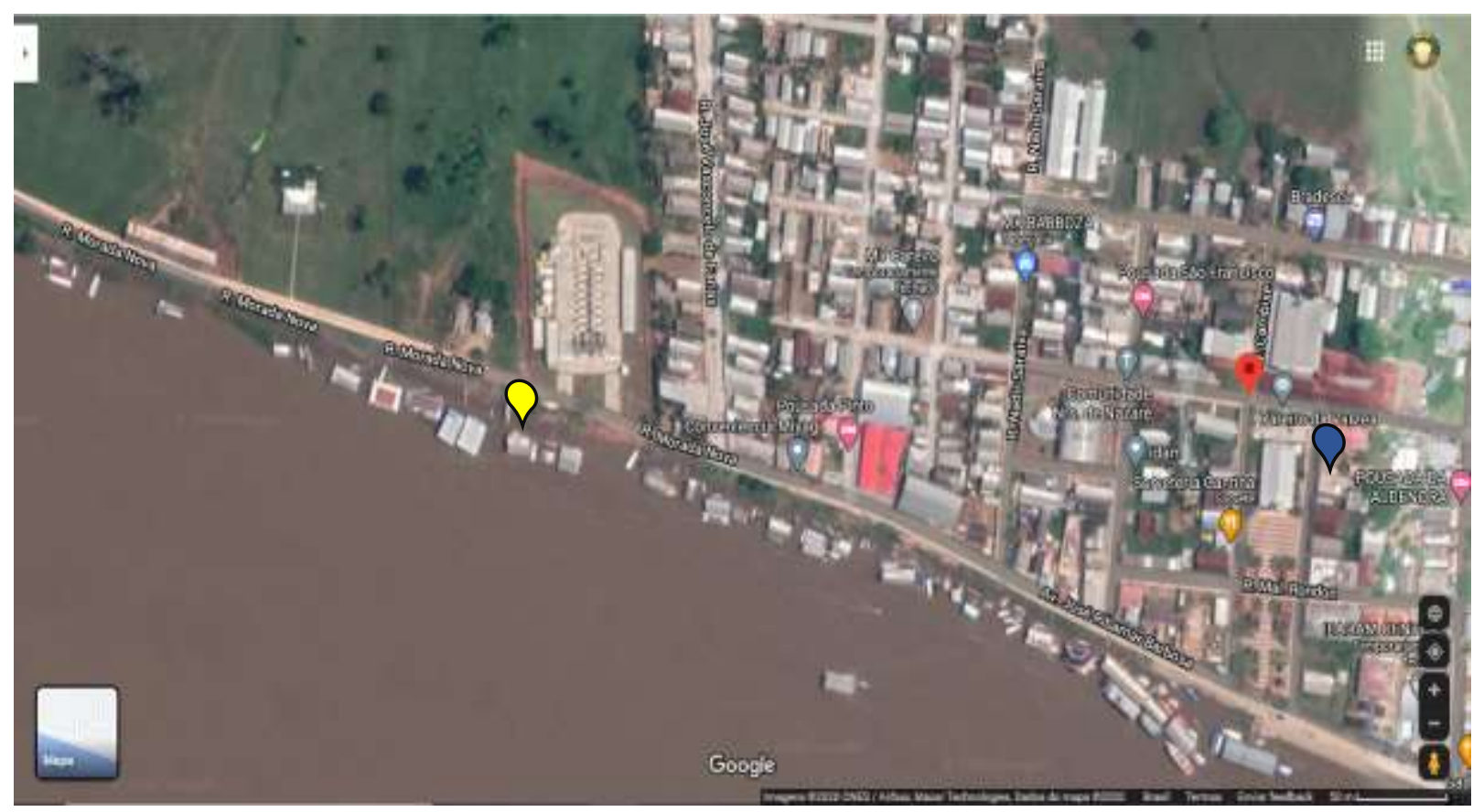

Fonte: Google Maps (2020).

A amostragem da água (20 L) foi realizada conforme a NBR 9.898/87 (ABNT, 1987) e as amostras foram preservadas de acordo com o Standard Methods for the Examination of Water and Wastewater (APHA, 2012) e os reagentes químicos 
utilizados apresentavam pureza de grau analítico. As análises físico-químicas da água bruta coletada no Rio Solimões foram realizadas nos laboratórios da ETA e da UFAM (Campus Manaus) de acordo com a Tabela 1.

Tabela 1. Frequência e parâmetros realizados no monitoramento do manancial.

\begin{tabular}{|c|c|c|c|}
\hline Análises & Parâmetros & Per & \\
\hline \multirow{10}{*}{ Físico-químicas } & $\mathrm{pH}$ & \multirow{7}{*}{ Diário } & \multirow{7}{*}{$2 x$} \\
\hline & Turbidez & & \\
\hline & Cor Aparente & & \\
\hline & Temperatura & & \\
\hline & Acidez & & \\
\hline & Alcalinidade & & \\
\hline & Dureza & & \\
\hline & Amônia & \multirow{6}{*}{ Semanal } & \multirow{6}{*}{$2 \mathrm{x}$} \\
\hline & Ferro & & \\
\hline & Sulfeto & & \\
\hline \multirow{3}{*}{ Bacteriológicas } & Coliformes Totais & & \\
\hline & Coliformes Termotolerantes & & \\
\hline & Bactérias Heterotróficas & & \\
\hline
\end{tabular}

Fonte: Autores.

Os ensaios físico-químicos foram realizados em dois períodos diariamente, no início da manhã e no final da tarde, para verificação das características do rio, com exceção das análises para amônia, ferro e sulfeto que foram realizadas duas vezes na semana, seguindo a metodologia APHA (2012) e utilizando um fotocolorímetro Alfakit modelo AT10P. As leituras de $\mathrm{pH}$ e temperatura foram realizadas em um pHmetro HACH modelo AT100P. Para a determinação da Cor Aparente foi utilizado um espectrofotômetro portátil DR1900 com comprimento de onda na faixa de 340 a $800 \mathrm{~nm}$. As análises de Turbidez foram obtidas utilizando um turbidímetro microprocessado Alfakit modelo Plus II pelo método nefelométrico. Já para determinar a Acidez foi utilizada a equação 1 seguindo a metodologia de Macêdo (2005).

$$
\text { Acidez }(\mathrm{ppm})=\frac{\mathrm{V}_{\mathrm{NaOH}^{*}} \mathrm{M}_{\mathrm{NaOH}^{*}} \mathrm{MM}_{\mathrm{CaCO}_{3}} * 1000}{\mathrm{~V}_{\text {amostra }^{* 2}}}
$$

sendo, $\mathrm{V}_{\mathrm{NaOH}} \mathrm{o}$ volume de $\mathrm{NaOH}$ gasto na titulação $(\mathrm{mL}), \mathrm{M}_{\mathrm{NaOH}}$ a concentração molar do $\mathrm{NaOH}$ padronizado (mol/L), $\mathrm{V}_{\text {amostra }}$ o volume da água $(\mathrm{mL})$ e $\mathrm{MM}_{\mathrm{CaCO}}$ a massa molar do $\mathrm{CaCO}_{3}(\mathrm{~g} / \mathrm{mol})$.

Para a determinação da Alcalinidade utilizou-se a equação 2 e o procedimento adotado de acordo com Macêdo (2005).

$$
\text { Alcalinidade }(\mathrm{ppm})=\frac{\mathrm{V}_{\mathrm{H} 2 \mathrm{SO}} * \mathrm{M}_{\mathrm{H} 2 \mathrm{SO}}{ }^{*} \mathrm{MM}_{\mathrm{CaCO}^{*}} * 1000}{\mathrm{~V}_{\text {amostra }}}
$$

sendo, $\mathrm{V}_{\mathrm{H} 2 \mathrm{SO} 4}$ o volume de $\mathrm{H}_{2} \mathrm{SO}_{4}(\mathrm{~mL}), \mathrm{M}_{\mathrm{H} 2 \mathrm{SO} 4}$ a concentração calculada de $\mathrm{H}_{2} \mathrm{SO}_{4}(\mathrm{~mol} / \mathrm{L}), \mathrm{MM}_{\mathrm{CaCO} 3}$ a massa molar do $\mathrm{CaCO}_{3}(100,086 \mathrm{~g} / \mathrm{mol})$ e $\mathrm{V}_{\text {amostra }}$ o volume da amostra $(\mathrm{mL})$.

A Dureza Total foi efetuada por titulação EDTA, após a amostra ser tamponada para o pH 10, seguindo a metodologia adotada por ANA (2011) e utilizando a equação 3. 


$$
\text { Dureza Total }\left(\mathrm{mg} \text { de } \mathrm{CaCO}_{3}\right)=\frac{\mathrm{C}_{\mathrm{EDTA}} * \mathrm{~V}_{\mathrm{EDTA} * \mathrm{MM}_{\mathrm{CaCO}_{3}} * 1000}}{\mathrm{~V}_{\text {amostra }}}
$$

sendo, $\mathrm{V}_{\text {EDTA }}$ o volume utilizado na titulação $(\mathrm{mL}), \mathrm{C}_{\mathrm{EDTA}}$ a concentração da solução de EDTA (mol/L), MM $\mathrm{CaCO}$ a massa molar do $\mathrm{CaCO}_{3}(\mathrm{~g} / \mathrm{mol})$ e $\mathrm{V}_{\text {amostra }}$ o volume da amostra titulado (100mL).

As análises microbiológicas foram realizadas duas vezes na semana para verificar três qualidades de bactérias coliformes totais, Escherichia Coli e bactérias heterotróficas, empregando-se a metodologia enzimática do substrato definido (Colilert e Simplate, respectivamente). Este método utiliza o reagente Colilert e se baseia na ação de enzimas produzidas pelos Coliformes, por meio da alteração de cor e pelo aparecimento de fluorescência (Araújo \& Andrade, 2020; Silva et al., 2017). Já o método utilizado para quantificar o NMP (número mais provável) das bactérias heterotróficas foi o SimPlate.

Todas as amostras foram caracterizadas para verificação de conformidade nas coletas e para comparação no final do procedimento de coagulação/floculação e sedimentação, por meio do controle de qualidade para Turbidez e Cor Aparente, visando o atendimento dos padrões de potabilidade exigidos pela Portaria MS/GM n 05 (Brasil, 2017).

\subsection{Ensaios de bancada (Jar Test)}

Para verificar a concentração ideal na ETA para cada coagulante em nível de bancada foi realizado o teste de Jarros, que consiste na análise das diferentes faixas de concentrações dos coagulantes comerciais em escala laboratorial. $O$ equipamento Jar Test (Alfakit modelo 3PV AT403) utilizado nos ensaios compreende de 3 jarros com capacidade de 2 litros cada e velocidade de agitação de 0 a 180 rpm. O procedimento adotado seguiu Di Bernardo et al. (2020). As fases dos ensaios do Jar Test simulam as três etapas do processo da ETA: coagulação, floculação e decantação. Inicialmente foram preparadas as soluções descritas na Tabela 2 e para o cálculo das concentrações utilizados nos jarros aplicou-se a equação 4.

$$
q_{c}=\frac{V * C}{C s}
$$

sendo, "q $\mathrm{q}_{\mathrm{c}}$ " a quantidade de coagulante a ser pipetada $(\mathrm{mL})$; "V" o volume do jarro (mL); "C" a concentração a ser testada (ppm); e Cs a concentração do sulfato (ppm).

Tabela 2. Preparo das soluções utilizadas para o teste de jarros.

\begin{tabular}{lc}
\hline \multicolumn{1}{c}{ Produto Químico } & Concentração \\
\hline Coagulante 1: Sulfato de Alumínio $\left(\mathrm{Al}_{2} \mathrm{SO}_{4}\right)$ & $10 \%$ \\
Coagulante 2: Cloreto Férrico $\left(\mathrm{Fe}_{2} \mathrm{Cl}_{3}\right)$ & $10 \%$ \\
Coagulante 3: Policloreto de Alumínio (PAC) & $10 \%$ \\
\hline Polímero não-iônico & $10 \%$ \\
Cal (hidróxido de cálcio) hidratada & $3 \mathrm{~g} / \mathrm{L}$ \\
\hline
\end{tabular}

Fonte: Autores.

Para o início dos testes foram preparados alguns Jarros-mãe para determinar o pH ótimo de floculação com o sulfato de alumínio (utilizado na ETA) e a partir dele foi realizado o estudo. A Tabela 3 apresenta os testes iniciais para a determinação da faixa de concentração e o pH dos testes de jarros. 
Tabela 3. Testes iniciais para os Jarros-mãe.

\begin{tabular}{lccc}
\hline \multicolumn{1}{c}{ Dados } & Jarro-Mãe 1 & Jarro-Mãe 2 & Jarro-Mãe 3 \\
\hline $\mathrm{pH}$ & 7,5 & 7,39 & 7,21 \\
Água Bruta & $2000 \mathrm{~mL}$ & $2000 \mathrm{~mL}$ & $2000 \mathrm{~mL}$ \\
Sulfato de Alumínio (coagulante da ETA) & $50 \mathrm{ppm}$ & $40 \mathrm{ppm}$ & $30 \mathrm{ppm}$ \\
Polímero não-iônico (Floculante da ETA) & $0,5 \mathrm{ppm}$ & $0,5 \mathrm{ppm}$ & $0,4 \mathrm{ppm}$ \\
Cal hidratada (alcalinizante) & $2 \mathrm{ppm}$ & 0 & 0 \\
\hline
\end{tabular}

Fonte: Autores.

Portanto, a partir do jarro-mãe 3 os testes seguiram com a faixa ótima de concentração para a coagulação da água bruta retirada do manancial. Com base nos testes iniciais a Tabela 4 descreve os ensaios para as faixas de concentrações a serem avaliadas para cada coagulante. A dosagem ideal do coagulante para a ocorrência da sedimentação foi determinada a partir da adição de quantidades crescentes com o pH 7 (predefinido nos testes iniciais).

Tabela 4. Faixas de concentrações para os ensaios de Jar Test.

\begin{tabular}{|c|c|c|c|c|c|}
\hline \multirow[b]{2}{*}{ Experimento } & \multicolumn{2}{|c|}{ Condições dos Ensaios } & \multirow{2}{*}{$\begin{array}{c}\text { Ensaio 1 } \\
\text { C. Floc (ppm) }\end{array}$} & \multirow{2}{*}{$\begin{array}{c}\text { Ensaio } 2 \\
\text { C. Floc (ppm) }\end{array}$} & \multirow{2}{*}{$\begin{array}{c}\text { Ensaio 3 } \\
\text { C. Floc (ppm) }\end{array}$} \\
\hline & C. Coag (ppm) & $\mathrm{pH}$ & & & \\
\hline 10 & 25 & 7,0 & 0,3 & 0,2 & 0,1 \\
\hline 9 & 23 & 7,0 & 0,3 & 0,2 & 0,1 \\
\hline 8 & 21 & 7,0 & 0,3 & 0,2 & 0,1 \\
\hline 7 & 19 & 7,0 & 0,3 & 0,2 & 0,1 \\
\hline 6 & 17 & 7,0 & 0,3 & 0,2 & 0,1 \\
\hline 5 & 15 & 7,0 & 0,3 & 0,2 & 0,1 \\
\hline 4 & 13 & 7,0 & 0,3 & 0,2 & 0,1 \\
\hline 3 & 11 & 7,0 & 0,3 & 0,2 & 0,1 \\
\hline 2 & 9 & 7,0 & 0,3 & 0,2 & 0,1 \\
\hline 1 & 7 & 7,0 & 0,3 & 0,2 & 0,1 \\
\hline
\end{tabular}

Fonte: Autores.

Ao final de cada ensaio foram coletadas amostras nos jarros e realizadas análises de turbidez e cor aparente, assim como a determinação de alumínio dissolvido, para os coagulantes Sulfato de Alumínio e Policloreto de Alumínio, e ferro dissolvido, para o coagulante Cloreto Férrico.

\subsection{Aumento de escala (Teste na ETA)}

A Estação de Tratamento de Águas (ETA) da cidade do Careiro da Várzea é do tipo compacta, de clarificação com filtro de areia de dupla ação, com vazão de $30 \mathrm{~m}^{3} / \mathrm{h}$. É uma estação metálica, de funcionamento sob pressão, decantação acelerada e lodos suspensos. As soluções foram preparadas em tanques com o auxílio de misturadores, onde ocorreram a dispersão e diluição dos reagentes. A cuba do coagulante foi preparada utilizando a concentração de acordo com os ensaios de Jar Test, para um volume de 100 litros. O monitoramento com os coagulantes foi efetuado durante 24 horas, realizando análises de Turbidez e Cor Aparente a cada hora durante o processo. A lavagem dos filtros foi efetuada de 12/12 horas para garantir a limpeza entre cada mudança de coagulante. 


\section{Resultados e Discussão}

\subsection{Monitoramento das águas do Rio Solimões no ponto de captação}

O pH do Rio Solimões no ponto de captação apresentou características básicas, com variações na escala de 8 (Figura 3A). É classificado como rio de águas brancas, com elevada quantidade de material em suspensão e sais dissolvidos provenientes dos Andes, influenciando desta forma nas suas propriedades físico-químicas. De acordo com Queiroz \& Tomaz Neto (2019) o rio possui grande influência geológica, corroborando com os dados analisados, uma vez que, os minerais silicatos e espécies de $\mathrm{CO}_{2}$ deixam o $\mathrm{pH}$ mais alcalino, e a dissolução dos silicatos por hidrólise consome íons $\mathrm{H}^{+}$e eleva o pH das águas.

Outro parâmetro que sofre interferência pela geoquímica do Rio Solimões é a Turbidez (Figura 3B), pois na água encontram-se muitos sólidos em suspensão, característica do fenômeno conhecido por terras caídas, que consiste no deslizamento do solo, que é frágil, das margens do manancial, além de apresentar uma velocidade média de $6 \mathrm{~km} / \mathrm{h}$, o que causa erosão ao longo de sua calha (Silva \& Noda, 2016). Portanto, a faixa encontrada de turbidez de 75 a 150 NTU, aponta valores altos, com elevada presença de materiais em suspensão, desse modo o tipo de coagulante utilizado é de suma importância para retirada dessas partículas do rio.

A Cor aparente é o parâmetro indicador da presença de metais, humus, plâncton dentre outras substâncias dissolvidas na água (Lima Jr \& Abreu, 2018). Pela Figura 3C pode-se observar muitas variações nos ensaios realizados, principalmente no decorrer da semana, isto devido a movimentação de embarcações nas proximidades. Outro fator que provoca alterações é a época do monitoramento, que compreende o período de estiagem ou seca, deixando o rio mais adensado. As aferições de Temperatura (Figura 3D) indicaram que no início do dia obteve-se valores mais baixos, enquanto que no final do dia predominaram valores mais elevados, devido a maior incidência da radiação solar, vale lembrar que temperaturas mais elevadas diminuem a solubilidade dos gases e aumentam a taxa de transferência de gases, o que pode gerar mau cheiro e liberação de odores.

Os ensaios de acidez e de alcalinidade são importantes para verificar as possíveis mudanças de pH. A acidez pode ser proveniente do $\mathrm{CO}_{2}$ absorvido da atmosfera ou oriunda de matéria orgânica em decomposição, já a alcalinidade se dá por bicarbonatos, carbonatos e hidróxidos. Observa-se na Figura 3E que a Acidez do manancial permaneceu na faixa de 4,0 a 6,5 mg/L de $\mathrm{CaCO}_{3}$ indicando pouca presença de acidez carbônica no manancial estudado. Já a Alcalinidade (Figura 3F) apresentou valores elevados, na faixa de 35 a $45 \mathrm{mg} / \mathrm{L}$ de $\mathrm{CaCO}_{3}$, indicando a presença de carbonatos e bicarbonatos. Dessa forma, a água bruta possui características de tamponamento, resistindo a mudanças de pH (De Assis et al., 2017). A Figura 3G apresenta os resultados obtidos para a Dureza da água, que está relacionada a presença de cátions multivalentes. Pode-se observar que a dureza permaneceu na faixa de 30 a $55 \mathrm{mg} / \mathrm{L}$ de $\mathrm{CaCO}_{3}$, caracterizando o manancial como água branda e água dura. 
Figura 3. Análises físico-químicas da água bruta do Rio Solimões.
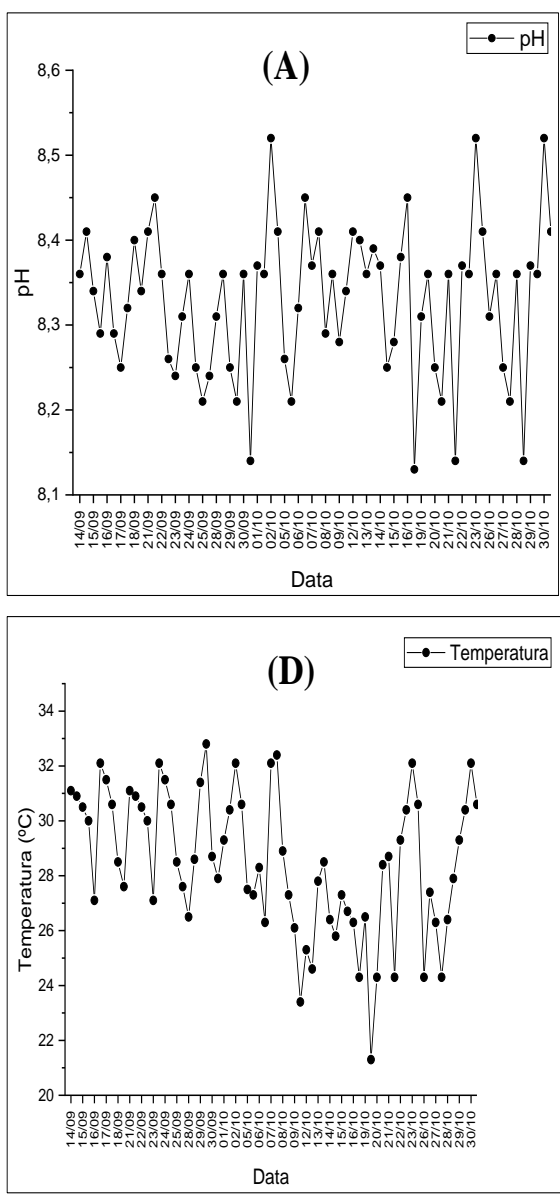
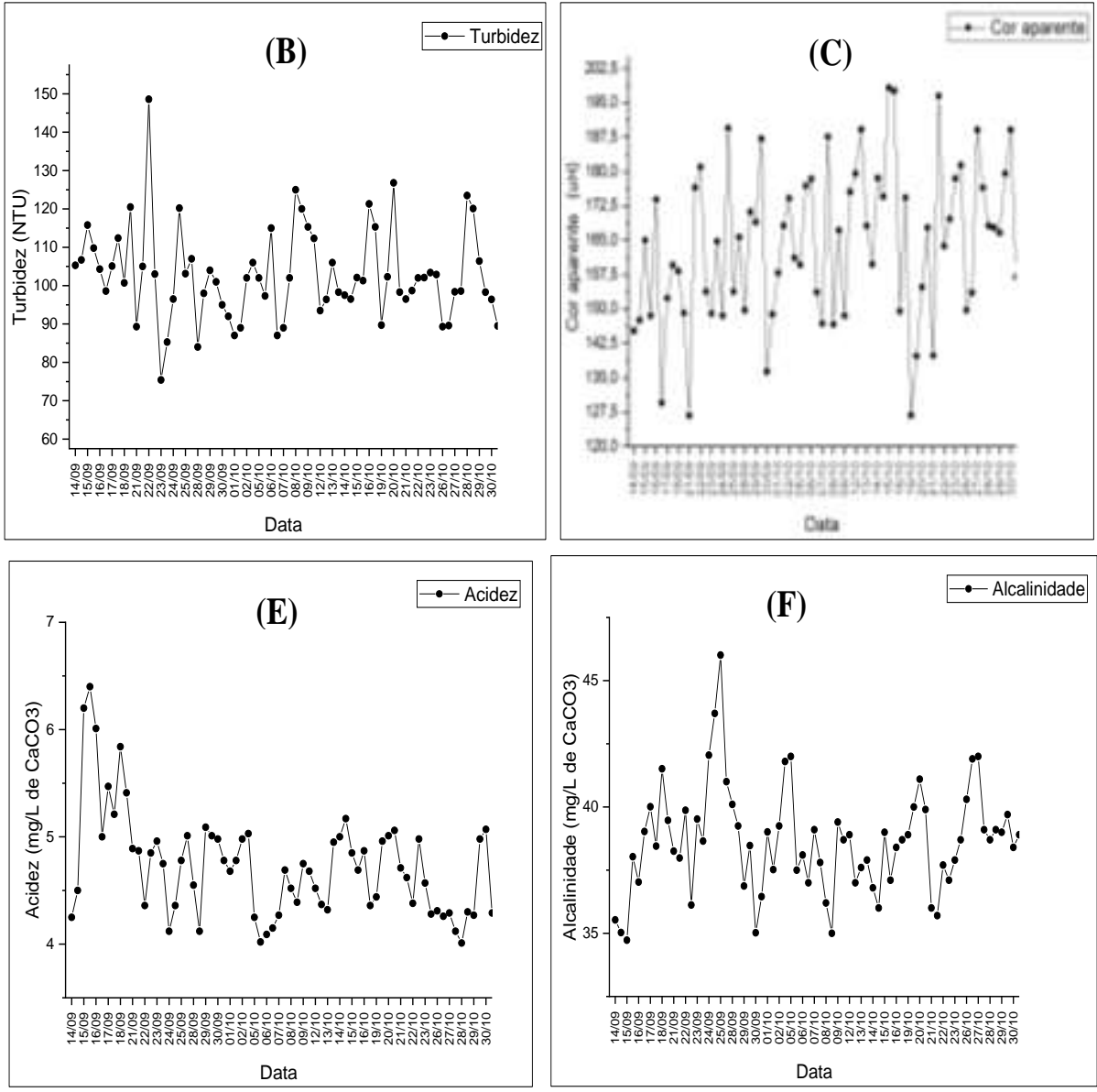

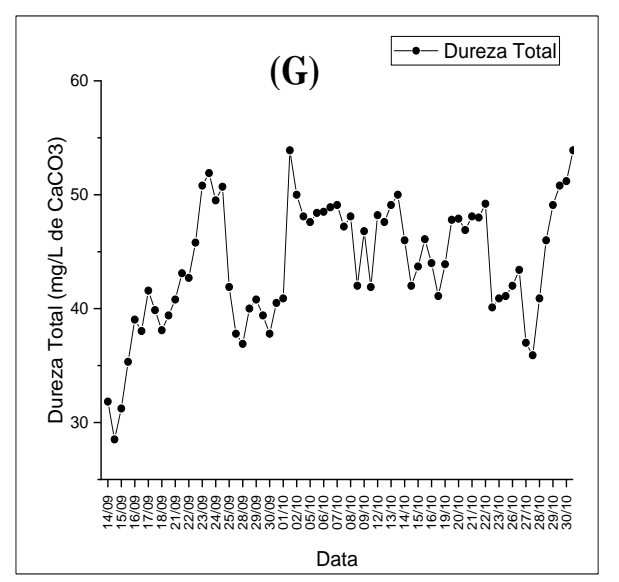

Fonte: Autores.

A Tabela 5 apresenta os resultados para a análises de metais. Nota-se que, para Amônia e Sulfeto não ocorreram grandes variações e os valores de ferro apresentaram-se acima da média, corroborando com De Sousa (2008) que encontrou uma média de $0,20 \mathrm{mg} / \mathrm{L}$ para o mesmo período. Isto se deve a diferença geográfica do ponto de coleta, pois De Sousa (2008) realizou análise no trecho Coari-Manaus. Esses valores de ferro estão ligados a localização, onde existem vários flutuantes no entorno. Para Amônia obteve-se uma média de 0,05 mg/L, resultando em um valor baixo de toxidade, uma vez que 7,7\% dos resultados de amônia foram considerados tóxicos para uma média de $\mathrm{pH}$ 8,4. A captação da água bruta estava situada nas margens da cidade, por conseguinte maior presença de atividade humana nas redondezas, logo o flutuante de captação foi distanciado da margem, o que favoreceu na redução dos valores dos parâmetros. 
Tabela 5. Resultados dos ensaios para determinação da concentração de metais.

\begin{tabular}{|c|c|c|c|c|}
\hline \multicolumn{2}{|c|}{ Monitoramento } & \multirow{2}{*}{$\frac{\text { Amônia }(\mathrm{mg} / \mathrm{L})}{0,05}$} & \multirow{2}{*}{$\begin{array}{c}\text { Ferro }(\mathrm{mg} / \mathrm{L}) \\
1,35\end{array}$} & \multirow{2}{*}{$\frac{\text { Sulfeto }(\mathrm{mg} / \mathrm{L})}{0,11}$} \\
\hline $140018 / 00$ & $1^{\mathrm{a}}$ análise & & & \\
\hline ל & $2^{\mathrm{a}}$ análise & 0,07 & 0,52 & 0,02 \\
\hline \multirow{2}{*}{ 21/09 a 25/09 } & $1^{\mathrm{a}}$ análise & 0,06 & 1,38 & 0,10 \\
\hline & $2^{\mathrm{a}}$ análise & 0,08 & 0,63 & 0,08 \\
\hline \multirow{2}{*}{$28 / 09$ a $02 / 10$} & $1^{\mathrm{a}}$ análise & 0,05 & 1,33 & 0,09 \\
\hline & $2^{\mathrm{a}}$ análise & 0,06 & 1,39 & 0,12 \\
\hline \multirow{2}{*}{$05 / 10$ a $09 / 10$} & $1^{\mathrm{a}}$ análise & 0,05 & 1,00 & 0,18 \\
\hline & $2^{\mathrm{a}}$ análise & 0,06 & 1,25 & 0,30 \\
\hline \multirow{2}{*}{$12 / 10$ a $16 / 10$} & $1^{\mathrm{a}}$ análise & 0,07 & 1,23 & 0,17 \\
\hline & $2^{\mathrm{a}}$ análise & 0,02 & 1,10 & 0 \\
\hline \multirow{2}{*}{$19 / 10$ a $23 / 10$} & $1^{\mathrm{a}}$ análise & 0 & 1,51 & 0 \\
\hline & $2^{\mathrm{a}}$ análise & 0,06 & 1,38 & 0,13 \\
\hline \multirow{2}{*}{$26 / 10$ a $30 / 10$} & $1^{\mathrm{a}}$ análise & 0,06 & 1,21 & 0,12 \\
\hline & $2^{\mathrm{a}}$ análise & 0,08 & 0,62 & 0,05 \\
\hline
\end{tabular}

Fonte: Autores.

Quanto aos parâmetros bacteriológicos (Tabela 6) foram observados a presença de bactérias em todas as amostras. Como o ponto de captação (flutuante) encontrava-se próximo ao perímetro urbano, já era previsto os valores alcançados, uma vez que em águas superficiais ocorre a presença destes microrganismos em taxas elevadas (Arcos et al., 2020). A turbidez possui significativa influência nestes parâmetros, o alto índice pode indicar contaminação, pois o material em suspensão é utilizado por microrganismos como abrigo, colonizando as partículas presentes e dificultando o processo de desinfecção da água (Silva, 2019).

Observou-se também um percentual menor de bactérias do grupo coliforme fecal quando comparado ao coliforme total, indicando que a microbiota pode ocasionar a inibição do crescimento de bactérias Escherichia coli. Esta correlação também foi sugerida por Silva (2019) que relataram baixo índice de Escherichia coli, provavelmente pela inibição por bactérias antagonistas, além da influência do pH sobre seu crescimento. Uma relação diretamente proporcional do aumento dos coliformes totais com os coliformes fecais já era esperado uma vez que a origem fecal dos coliformes pode ser a mesma, ou seja, a origem de resíduos de esgoto ou de produtos urbanos. 
Tabela 6. Resultados dos ensaios bacteriológicos no manancial.

\begin{tabular}{|c|c|c|c|c|}
\hline \multicolumn{2}{|c|}{ Monitoramento } & Coliformes Totais & Escherichia Coli & Bactérias Heterotróficas \\
\hline \multirow{2}{*}{$14 / 09$ a 18/09 } & $1^{\mathrm{a}}$ análise & 1011,2 & 533,5 & 29,9 \\
\hline & $2^{\mathrm{a}}$ análise & 920,8 & 216,4 & 37,2 \\
\hline \multirow{2}{*}{$21 / 09$ a $25 / 09$} & $1^{\mathrm{a}}$ análise & 1119,9 & 412,0 & 23,9 \\
\hline & $2^{\mathrm{a}}$ análise & 960,6 & 223,0 & 44,0 \\
\hline \multirow{2}{*}{$28 / 09$ a $02 / 10$} & $1^{\mathrm{a}}$ análise & 1011,2 & 257,2 & 19,7 \\
\hline & $2^{\mathrm{a}}$ análise & 1732,9 & 550,4 & 35,5 \\
\hline \multirow{2}{*}{$05 / 10$ a $09 / 10$} & $1^{\mathrm{a}}$ análise & 980,4 & 153,5 & 23,8 \\
\hline & $2^{\mathrm{a}}$ análise & 913,9 & 251,3 & 31,1 \\
\hline \multirow{2}{*}{$12 / 10$ a $16 / 10$} & $1^{\mathrm{a}}$ análise & 1011,2 & 412,0 & 20,4 \\
\hline & $2^{\mathrm{a}}$ análise & 1553,1 & 549,3 & 37,2 \\
\hline \multirow{2}{*}{$19 / 10$ a $23 / 10$} & $1^{\mathrm{a}}$ análise & 960,6 & 140,1 & 23,9 \\
\hline & $2^{\mathrm{a}}$ análise & 1732,9 & 516,3 & 44,0 \\
\hline \multirow{2}{*}{$26 / 10$ a $30 / 10$} & $1^{\mathrm{a}}$ análise & 1011,2 & 216,7 & 39,2 \\
\hline & $2^{\mathrm{a}}$ análise & 1046,2 & 509,9 & 41,4 \\
\hline
\end{tabular}

Fonte: Autores.

\subsection{Ensaios de bancada (Jar Test)}

Nos ensaios em escala laboratorial utilizando o equipamento Jar Test não houve adição de alcalinizante nem correção de $\mathrm{pH}$, pois a alcalinidade natural da água do manancial estava acima do necessário para a reação com os agentes coagulantes. A média da alcalinidade da água bruta para os ensaios foi $40 \mathrm{mg} / \mathrm{L}$ e do $\mathrm{pH} 8,35$.

Os resultados do Jar Test para o Ensaio 1 (Figuras 4A e 4B) utilizando Sulfato de Alumínio como coagulante apresentaram boa remoção da turbidez, principalmente para concentrações elevadas, atingindo 99,16\% para 25 ppm, porém, a remoção de cor aparente não foi tão eficaz, ficando atrás do Sulfato de Alumínio e do PAC. Ainda houve a ocorrência de superdosagem, na qual durante a etapa de floculação formam-se flocos grandes, o que torna prejudicial a etapa de filtração, conforme afirma Nandini \& Sheba (2016).

Ainda no Ensaio 1, agora utilizando o coagulante Cloreto Férrico observou-se excelente remoção da turbidez para as concentrações altas, com máximo de 99,38\%, assim como para a remoção de cor aparente (98,93\%) para 25 ppm. O ferro dissolvido apresentou valores aceitáveis e dentro dos padrões exigido pela Portaria MS/GM n 05/2017, conforme mostra a Tabela 7. Já o Policloreto de Alumínio (PAC), em comparação com os outros coagulantes, não apresentou bons resultados, além de que para as concentrações mais altas (23 e $25 \mathrm{ppm}$ ) os valores para o alumínio dissolvido ficaram fora do limite estabelecido pela Portaria MS/GM n 05/2017 que é de 0,2 mg/L (Tabela 8), e de acordo com Guo et al. (2015) o excesso de sais de alumínio são prejudiciais aos organismos humanos e vivos.

No Ensaio 2 (Figuras 4C e 4D) ao utilizar o Sulfato de Alumínio observaram-se melhores percentuais de remoção de turbidez para concentrações mais elevadas $(99,07 \%$ para 25 ppm), porém menores percentuais para remoção de cor aparente (96,21\% a 25 ppm), em comparação com o Ensaio 1. Para o Cloreto Férrico os experimentos apresentaram melhores remoções de turbidez e cor aparente, 99,95\% e 99,13, respectivamente para 25 ppm, além do ferro dissolvido apresentar valores menores (ver Tabela 7). Já ao utilizar o Policloreto de Alumínio os resultados tanto da remoção de turbidez quanto da remoção de cor 
aparente não foram mais eficazes em relação ao Ensaio 1, e ainda ocorreram não conformidades para o alumínio dissolvido de acordo com os limites estabelecidos pela Portaria MS/GM n ${ }^{\circ}$ 05/2017.

Tabela 7. Determinação de ferro dissolvido para os três ensaios Jar Test utilizando $\mathrm{Fe}_{2} \mathrm{Cl}_{3}$.

\begin{tabular}{cccc}
\hline Experimento & Ensaio 1 & Ensaio 2 & Ensaio 3 \\
\hline 10 & 0,19 & 0,20 & 0,19 \\
\hline 9 & 0,08 & 1,31 & 0,08 \\
\hline 8 & 0,01 & 0,08 & 0,01 \\
\hline 7 & 0,07 & 0,10 & 0,07 \\
\hline 6 & 0,01 & 0,08 & 0,01 \\
\hline 5 & 0,03 & 0,07 & 0,03 \\
\hline 4 & 0,02 & 0,08 & 0,02 \\
\hline 3 & 0,07 & 0,06 & 0,07 \\
\hline 2 & 0,01 & 0,02 & 0,01 \\
\hline 1 & 0,07 & 0,03 & 0,07
\end{tabular}

Fonte: Autores.

Tabela 8. Determinação de alumínio dissolvido para os três ensaios Jar Test.

\begin{tabular}{ccccccc}
\hline Experimento & $\begin{array}{c}\text { Ensaio 1 } \\
\left(\mathrm{Al}_{2} \mathrm{SO}_{4}\right)\end{array}$ & $\begin{array}{c}\text { Ensaio 1 } \\
(\mathrm{PAC})\end{array}$ & $\begin{array}{c}\text { Ensaio 2 } \\
\left(\mathrm{Al}_{2} \mathrm{SO}_{4}\right)\end{array}$ & $\begin{array}{c}\text { Ensaio 2 } \\
(\mathrm{PAC})\end{array}$ & $\begin{array}{c}\text { Ensaio 3 } \\
\left(\mathrm{Al}_{2} \mathrm{SO}_{4}\right)\end{array}$ & $\begin{array}{c}\text { Ensaio 3 } \\
(\mathrm{PAC})\end{array}$ \\
\hline 10 & 1,62 & $\mathrm{NC}$ & 1,85 & $\mathrm{NC}$ & 1,87 & 1,98 \\
\hline 9 & 1,01 & $\mathrm{NC}$ & 1,74 & 1,87 & 0,93 & $\mathrm{NC}$ \\
\hline 8 & 0,97 & 0,85 & 0,97 & 0,92 & 0,97 & 1,78 \\
\hline 7 & 0,16 & 0,28 & 0,58 & 0,83 & 0,84 & 1,32 \\
\hline 6 & 0,04 & 0,41 & 0,43 & 0,90 & 0,48 & 1,40 \\
\hline 5 & 0,09 & 0,27 & 0,26 & 0,56 & 0,51 & 0,27 \\
\hline 4 & 0,05 & 0,27 & 0,14 & 0,27 & 0,13 & 0,27 \\
\hline 3 & 0,03 & 0,19 & 0,09 & 0,34 & 0,05 & 0,19 \\
\hline 2 & 0,06 & 0,03 & 0,10 & 0,09 & 0,07 & 0,03 \\
\hline 1 & 0,02 & 0,03 & 0,03 & 0,12 & 0,03 & 0,03 \\
\hline
\end{tabular}

$\mathrm{NC}=$ Não Conforme com a Portaria MS/GM n ${ }^{\circ}$ 05/2017. Fonte: Autores. 
Figura 4. Gráficos comparativos para a remoção de Turbidez (A) e remoção de Cor (B) para o Ensaio 1, Ensaio 2 e Ensaio 3 utilizando os diferentes coagulantes.
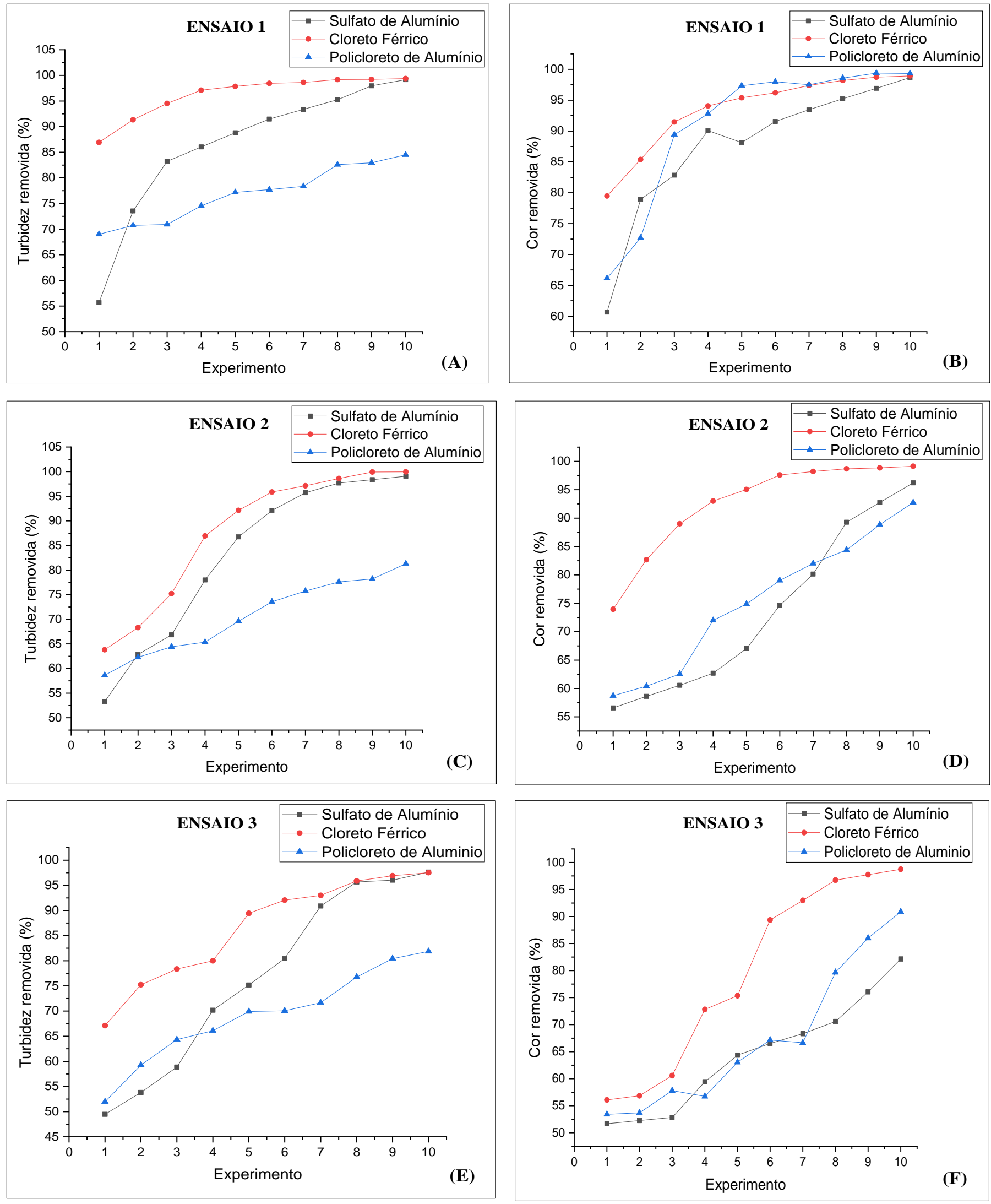

Fonte: Autores. 
Para os experimentos realizados no Ensaio 3 (Figuras 4E e 4F), utilizando a menor dosagem de floculante (0,1 ppm), observou-se que a tanto a remoção de turbidez quanto a remoção de cor para o $\underline{\text { Sulfato de Alumínio, }} \underline{\text { Cloreto Férrico } \mathrm{e}}$ Policloreto de Alumínio apresentaram resultados ainda menos eficazes, demonstrando que se torna necessária a utilização de um agente coadjuvante (polímero não iônico) para o processo de floculação (Rodrigues et al., 2015). A Figura 5 apresenta o equipamento Jar Test sendo utilizado na avaliação dos coagulantes.

Figura 5. Jar Test, sendo a) Sulfato de Alumínio; b) Cloreto Férrico; c) Policloreto de Alumínio.

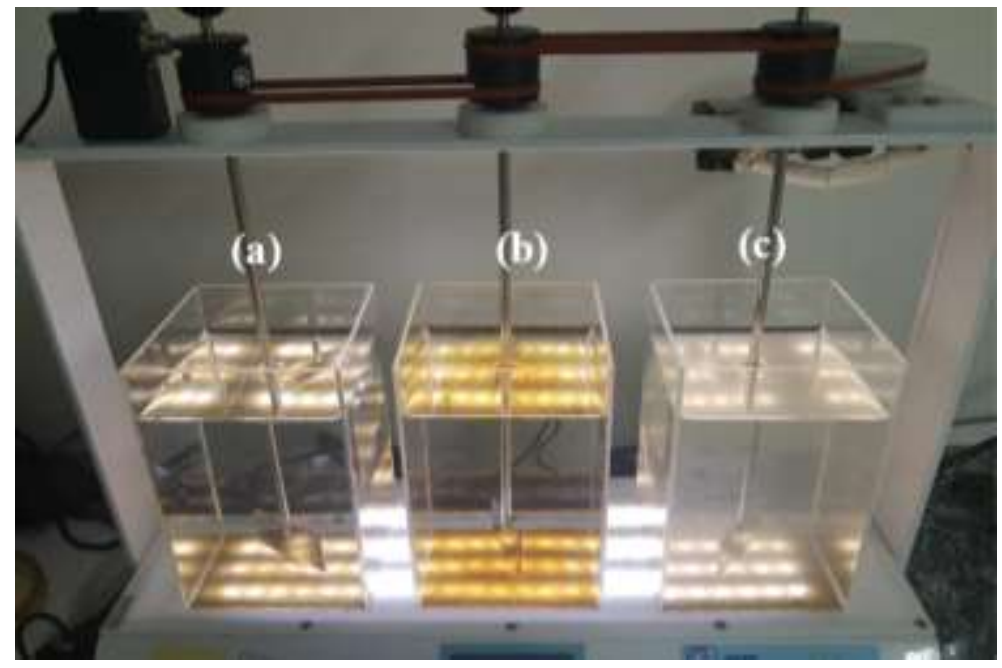

Fonte: Autores.

\subsection{Aumento de escala (Teste piloto na ETA)}

A Figura 6 apresenta uma análise visual comparativa das águas coletadas durante o teste piloto na Estação de Tratamento de Água (ETA) com os coagulantes comerciais. Pode-se observar pela Figura 6A um aspecto visual amarelado e bastante turvo para a água bruta do Rio Solimões. Já pelas Figuras 6B, 6C e 6D observam-se que os tratamentos efetuados com os coagulantes proporcionaram nas amostras de saída um perfil visual incolor numa escala $6 \mathrm{C}>6 \mathrm{~B}>6 \mathrm{D}$, ou seja, o confirmando um melhor desempenho para o coagulante Cloreto Férrico.

Figura 6. Amostras de coletas da água bruta do Rio Solimões (A), água da ETA utilizando Sulfato de Alumínio, do filtro e da saída (B) água da ETA utilizando Cloreto Férrico, do filtro e da saída (C) e, água da ETA utilizando Policloreto de Alumínio, do filtro e da saída (D).
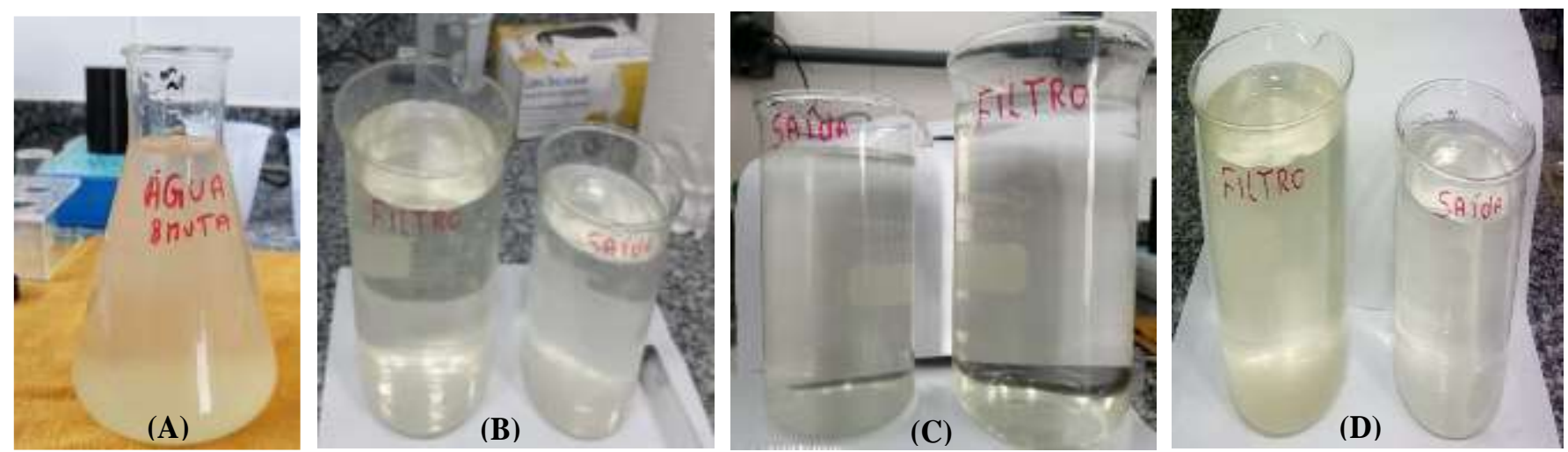

Fonte: Autores. 
A Figura 7A mostra o comportamento da turbidez e da cor aparente verificados durante o período de testes na ETA utilizando a melhor dosagem de Sulfato de Alumínio testada a nível de bancada, ou seja 19 ppm do coagulante e 0,3 ppm de floculante, pois acima destes valores, o alumínio dissolvido ficou fora dos limites estabelecido pela Portaria MS/GM n ${ }^{\circ} 05$ (Brasil, 2017). Ocorreram também grandes variações na turbidez nas primeiras 12h, porém após a lavagem dos filtros os resultados permaneceram na faixa de 2,0 NTU, isto verificou-se devido ao Sulfato de Alumínio operar de forma satisfatória em águas com alta turbidez e elevado $\mathrm{pH}$ de entrada.

Figura 7. Monitoramento da qualidade da água com a dosagem ótima utilizando o Sulfato de Alumínio (A), Cloreto Férrico (B) e Policloreto de Alumínio (C).
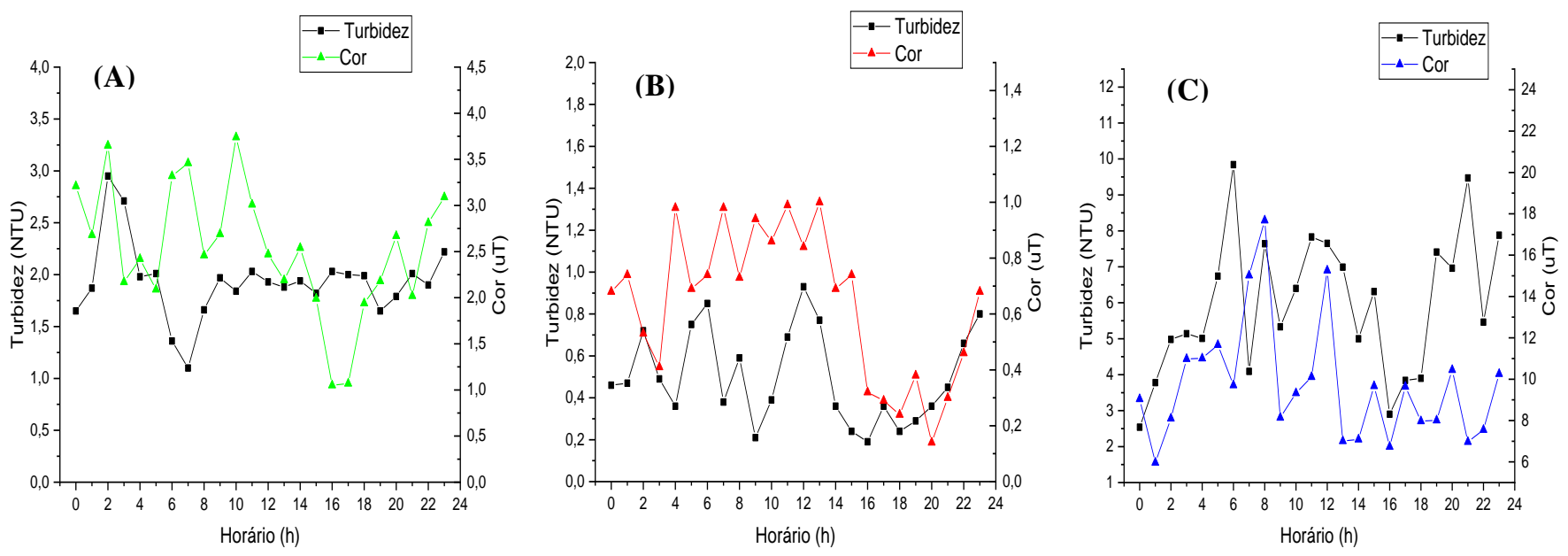

Fonte: Autores.

Para o monitoramento na ETA utilizando o coagulante Cloreto Férrico (Figura 7B) observou-se que o tratamento em escala aumentada apresentou bons resultados, uma vez que, a dosagem ótima averiguada nos testes laboratoriais, foi de 20 ppm de coagulante e $0,2 \mathrm{ppm}$ de floculante, com uma melhor redução do $\mathrm{pH}$, assim como o ferro dissolvido que também foi levado em consideração, permanecendo abaixo do limite estabelecido pela portaria que é de $0,2 \mathrm{mg} / \mathrm{L}$. Após a lavagem dos filtros (12h de processo) houve melhora significativa nos resultados, conforme pode ser observado na amostra de água da Figura 6C, a qual não apresenta turbidez nem alterações de cor visualmente.

Para o Policloreto de Alumínio, a dosagem ótima utilizada durante o processo (Figura 7C) mostrou que, em comparação com os outros coagulantes, obteve-se resultados menos eficientes, uma vez que a dosagem ótima para o processo de tratamento foi de 19 ppm do coagulante e $\mathbf{0 , 3}$ ppm do floculante, pois acima destas características, o alumínio dissolvido apresentou valores fora dos limites estabelecidos pela portaria vigente. Os resultados para cor aparente foram melhores, em comparação com a turbidez, porém, após a lavagem dos filtros, não ocorreram muitas alterações nos resultados, permanecendo na faixa de 7 NTU para turbidez e 12 uT para cor aparente. A Figura 6D mostra o perfil visual da água após o tratamento, encontrando-se turva e amarelada, o que indica um desempenho não satisfatório para a remoção da turbidez e cor aparente.

\section{Conclusão}

A caracterização físico-química do manancial no ponto de captação da água bruta é de suma importância, pois dessa forma são delimitados todo o restante do projeto da ETA. O Rio Solimões apresentou características como sendo um corpo hídrico de águas brancas, com pH entre 7-8, facilitando o tratamento uma vez que não é necessário o uso de alcalinizantes nem acidificantes na água. A geologia e os sedimentos em suspensão contribuíram para manter o pH próximo da neutralidade, com 
características mais básicas. É importante destacar que a época na qual realizou-se o monitoramento foi de estiagem ou seca. A partir dos ensaios de bancada foi verificado que dentre os três coagulantes comerciais avaliados o Cloreto Férrico obteve melhor resultado para remoção de cor e turbidez, além dos resultados de ferro e alumínio dissolvidos avaliados durante a operação. Por fim, os testes na ETA corroboraram com os ensaios laboratoriais, confirmando uma melhor eficiência para o coagulante Cloreto Férrico de concentração 20 ppm com condições operacionais de 0,2 ppm de floculante e pH 7 .

\section{Referências}

ABNT. Associação Brasileira de Normas Técnicas. (1987). NBR 9898: Preservação e técnicas de amostragem de efluentes líquidos e corpos receptores Procedimento.

ANA. Agência Nacional de Águas. (2011). Guia nacional de coleta e preservação de amostras água, sedimento, comunidades aquáticas e efluentes líquidos. . ANA.

APHA (2012). Standard Methods for the Examination of Water and Wastewater. (22a ed.), American Public Health Association, 1360p.

Araújo, D. L., \& Andrade, R. F. (2020). Qualidade Físico-Química e Microbiológica da Água Utilizada em Bebedouros de Instituições de Ensino no Brasil: Revisão Sistemática da Literatura. Brazilian Journal of Health Review, 3 (4), 7301-7324.

Arcos, A. N., Silva, J. S., \& Cunha, H. B. (2020). Grupo coliforme fecal como indicador de balneabilidade em praia de água doce no rio Negro, Amazonas. Research, Society and Development, 9 (7), e238974015.

Brasil. Ministério da Saúde. (2017). Portaria de Consolidação MS/GM n 05, de 28 de setembro de 2017. Consolidação das normas sobre as ações e os serviços de saúde do Sistema Único de Saúde. Diário Oficial da União, Brasília-DF.

Cavalcanti, J. E. W. A. (2016). Manual de tratamento de efluentes industriais. (3a ed.), Engenho Editora Técnica Ltda., 520p.

De Assis, D. M. S., Lima, A. B., Silva, E. R. M., Silva, A. S., \& Barbosa, I. C. C. Avaliação dos parâmetros físico-químicos da água de abastecimento em diferentes bairros do Município de Salvaterra (Arquipélago do Marajó, PA). Revista Virtual de Química, 9 (5), $1825-1839$.

De Sousa, A. K. F. (2008) Variação sazonal e espacial da concentração de elementos-traço nos rios Urucu, Solimões e Negro - Amazonas ocidental, Brasil. (Dissertação de Mestrado) PPGQ/ICE, Universidade Federal do Amazonas.

Di Bernardo, L., Dantas, A. D. B., \& Voltan, P. E. N. (2020). Métodos e técnicas de tratamento de água. (3a ed.), LDiBe, 1246p.

Dos Santos, M. L. A. (2012) Estudos das características do lodo gerado na ETA da Escola de Especialistas de Aeronaútica e avaliação de uma destinação adequada. (Trabalho de Conclusão de Curso em Engenharia Industrial Química) Escola de Engenharia de Lorena, Universidade de São Paulo.

Guo B., Yu H., Gao B., Rong H., Dong H., Ma D., Li R., \& Zhao S. (2015). Coagulation performance and floc characteristics of aluminum sulfate with cationic polyamidine as coagulant aid for kaolin - humic acid treatment. J. Colloids \& Surface A: Physicochemical and Engineering Aspects, $481,476$.

Libânio, M. (2010). Fundamentos de qualidade e tratamento de água. (3a ed.), Editora Átomo, 496p.

Lima Jr, R. N., \& Abreu, F. O. M. S. (2018). Produtos Naturais Utilizados como Coagulantes e Floculantes para Tratamento de Águas: Uma Revisão sobre Benefícios e Potencialidades. Revista Virtual de Química, 10 (3), 709-735.

Macêdo, J. A. B. (2005). Métodos laboratoriais de análises físico-químicas e microbiológicas. (3a ed.), CRQ-MG, 601p.

Mendes, G. S. (2018). A dinâmica da paisagem e uso da terra: estudo de caso no distrito da Terra Nova, Careiro da Várzea-AM. (Dissertação de Mestrado). Programa de Pós-Graduação em Ciências do Ambiente e Sustentabilidade na Amazônia, Universidade Federal do Amazonas.

Nandini, G. K. M., Sheba, M. C. (2016) Emanating Trends in the Usage of Bio-coagulants in Potable Water Treatment: a Review. International Research Journal of Engineering and Technology, 3, 970-974.

Pavanelli, G. (2001). Eficiência de diferentes tipos de coagulantes na coagulação, floculação e sedimentação de água com cor ou turbidez elevada. (Dissertação de Mestrado) Escola de Engenharia de São Carlos, Universidade de São Paulo.

Queiroz, M. S., \& Tomaz Neto, A. G. (2019). A influência dos Rios Negro e Solimões nas comunidades rurais ribeirinhas no município de Iranduba Amazonas. XVII Simpósio Brasileiro de Geografia Física Aplicada, Fortaleza - CE.

Rodrigues, D. L. C., Hartwig, M. P, \& Gerber, M. D. (2015). Avaliação de Nitrogênio e Fósforo de Efluentes Tratados dos Abatedouros na Cidade de Pelotas/RS. Revista Eletrônica em Gestão, Educação e Tecnologia Ambiental, 19 (1), 389-397.

Santos, G. Z. B., Melo Filho, J. A., \& Manzato, L. (2018). Perspectivas de aplicações tecnológicas de lodo gerado no processo de tratamento de água dos rios Negro e Solimões. Matéria, 23 (3), e12167.

Silva, A. B., Brito, J. M., Duarte, J. S., \& Almeida, O. E. L. (2017). Análise microbiológica da água utilizada para consumo nas escolas de Esperança, Paraíba. Principia, 37, 11-17.

Silva, I. R. G. (2019). Avaliação quantitativa do tratamento da água utilizando os coagulantes tanino e cloreto férrico. (Trabalho de Conclusão de Curso em Engenharia Ambiental) Universidade Tecnológica Federal do Paraná. 
Research, Society and Development, v. 10, n. 13, e284101321127, 2021

(CC BY 4.0) | ISSN 2525-3409 | DOI: http://dx.doi.org/10.33448/rsd-v10i13.21127

Silva, S. H., \& Noda, S. N. (2016). A Dinâmica entre as águas e terras na Amazônia e seus efeitos sobre as várzeas. Ambiente \& Água - An Interdisciplinary Journal of Applied Science, 11 (2), 377-386.

Sun, W., Xia, C., Xu, M, Guo, J., \& Sun, G. (2016). Application of modified water quality indices as indicators to assess the spatial and temporal trends of water quality in the Dongjiang River. Ecological Indicators, 66, 306-312.

Von Sperling, M. (2014). Introdução à Qualidade das Águas e ao Tratamento de esgotos. (4a ed.), DESA/UFMG, 452p. 